\title{
DYNAMIC WORKLOAD FLUCTUATIONS IN DRIVER/NON-DRIVER CONVERSATIONAL DYADS
}

\author{
David L. Strayer, Francesco Biondi, \& Joel M. Cooper
}

University of Utah, Salt Lake City, Utah, USA

Email: David.Strayer@utah.edu,Francesco.Biondi@utah.edu,Joel.Cooper@psych.utah.edu

\begin{abstract}
Summary: We developed a new method for simultaneously assessing the workload of a driver and a non-driver engaged in natural conversation either in the vehicle or over a cell phone. For both the driver and non-driver, talking was found to be more demanding than listening and the pattern was identical for both passenger conversations and cell phone conversations. Operating the vehicle increased the workload for the driver over and above the conversation task. The effects of driving (or not) and talking (or not) were found to be additive. The data reveal a pattern of dynamic fluctuation in workload in driver/non-driver conversational dyads.
\end{abstract}

\section{OBJECTIVES}

Do passenger conversations impair driving to the same extent as cell phone conversations? The answer depends, in part, on the age and experience of the driver and passenger. The teen driver/passenger dyad is a distracting combination. For example, a video analysis by Carney et al., (2015) found that a driver conversing or otherwise interacting with a passenger was the most common factor in teen-driver crashes $(15 \%)$, followed by a driver being engaged in a cell phone conversation (12\%). However, a different pattern emerges when there is an adult driver/passenger dyad; the crash rate falls below 1.0 (Rueda-Domingo et al., 2004; Vollrath, Meilinger, \& Kruger, 2002). By contrast, when adult drivers are engaged in a cell phone conversation, there is an elevated in crash risk (Dingus et al., 2016; Redelmeier \& Tibshirani, 1997; McEvoy et al., 2005).

One hypothesis for this discrepant pattern is that adult passengers often help the driver by pointing out hazards and helping to navigate (Drews, Pasupathi, \& Strayer, 2004, 2008). Even though the workload that the driver experiences when engaged in a passenger conversation is the same as that associated with a cell phone conversation (Strayer et al., 2015), the passenger provides another set of eyes that help to compensate for the distracted driver (Strayer, et al., 2001). This suggests that the workload experienced by the driver and passenger dynamically fluctuate with the ebb and flow of the conversation. However, there is currently no direct evidence to indicate a reciprocal pattern of workload for the driver/passenger dyad - when the driver is talking, the passenger is listening and vice versa.

The current research used novel method for simultaneously assessing the workload of the driver and non-driver when they were engaged in either a passenger conversation or a cell phone conversation. This method used two yoked detection reaction time (DRT) devices to measure the dynamic workload when each member of the dyad was talking and when they were listening. Given that talking is often more mentally demanding than listening to an interlocutor (Coleman, Turrill, Cooper, \& Strayer, 2016), we predict that the workload would ebb and flow depending on who is the active speaker in the conversational dyad. 


\section{METHODS}

\section{Participants}

Twenty pairs ( $\mathrm{N}=40$ participants in total) of undergraduate ( 28 females) who were acquaintances at the University of Utah participated in this study. They had an average age of 23 years old and a driving experience ranging from 3 to 16 years with an average of 6.5 years. All participants had normal or corrected-to-normal visual acuity, a valid driver's license, and were fluent in English. All participants owned a cell phone and reported that they used it regularly while driving.

\section{Equipment}

A DriveSafety ${ }^{\mathrm{TM}} \mathrm{DS}-600$ simulator was used in this experiment. The DS-600 consists of a Ford Focus cab surrounded by three large screens encompassing a $270^{\circ}$ view. The simulated vehicle is based on the vehicular dynamics of a passenger sedan with automatic transmission. The driving scenario was built using DriveSafety HyperDrive Authoring Suite. A two-way, four-lane interstate highway scenario was created for this experiment. The roadway has four straight sections (10 miles each) connected by two wide-radius curves (1 mile each).

A customized "dual-DRT" device was developed that permitted simultaneous assessment of workload for both the driver and non-driver conversational dyad. The DRT protocol for each device followed the specifications outlined in ISO WD 17488 (2015). The DRT consisted of an LED light mounted to a flexible arm that was connected to a headband, a micro-switch attached to the participant's left thumb, and a dedicated microprocessor to handle all stimulus timing and response data. The light was positioned in the periphery of left eye of each participant (approximately $15^{\circ}$ to the left and $7.5^{\circ}$ above the participant's left eye). The DRT devices (one for the driver and one for the non-driver) were yoked so that the LED lights were presented simultaneously on each unit and the device was programmed to present a stimulus every 3-5 seconds. Participants responded to the light by pressing a micro-switch attached to their finger. Each DRT device was also fitted with a microphone to record the voice of each participant. The microphone was used to identify if the driver or non-driver was talking at any given point in time. A threshold of $50 \mathrm{~dB}$ was used for establishing who was talking.

Cellular service was provided by Sprint. Two Apple (Model iPhone 5) cellular phones running iOS 6 were used. Participants used Jawbone Bluetooth earpieces for the hands-free cell phone conversation.

\section{Design and Procedure}

An Experimental Condition (3 levels: single-task, passenger conversation, cell phone conversation) x Activity (2 levels: talking, listening) x Actor (2 levels: driver, non-driver) between-subject design was employed in the study. Each condition lasted approximately for 20 minutes and the order of these conditions was counterbalanced. Within each pair of participants, one drove the simulated vehicle (the driver) whilst the other participant either was engaged in a conversation with the driver (in passenger and cell phone conversation conditions) or did nothing (single-task condition). In the single-task condition, the driver, seated alone, drove the simulated 
vehicle. In the passenger conversation condition, the driver drove the simulated vehicle and engaged in a conversation with the non-driver sitting next to them. In the cell phone condition, the driver drove the simulated vehicle and engaged in a hands-free cell phone conversation with the other participant who was sitting in a different room (with no view of the simulator).

In both the passenger and cell phone conversation conditions, participants were instructed to have a natural conversation as they would in real life; no restrictions about the topics covered in the conversation were provided to them. In the three conditions, participants performed a detection response task (DRT) using the custom dual-DRT headsets, one device fitted to each of the participants. Participants were instructed to press the micro-switch every time they detected the light presented by the their headset. The presentation of the lights across the DRT devices was synchronized so that the lights were presented at the same time. Whenever one of the two participants pressed the micro-switch, the light disappeared on their headset but remained ON for the other participant's headset until they pressed their respective micro-switch. Reaction times for the two participants were collected and analyzed separately.

\section{RESULTS}

The mean RT data collected from the driver (filled circles) and non-driver (filled squares) are presented in Figure 1. A series of paired t-tests contrasted single-task performance for the driver when they were engaged in a passenger conversation and were talking, $t(1,19)=4.66, p<0.001$, or listening, $\mathrm{t}(19)=3.33, \mathrm{p}=0.004$, and when the driver was engaged in a cell phone conversation when they were talking, $t(1,19)=4.86, p<0.001$, or listening, $t(1,19)=3.49, p=0.002$. Compared to the single-task condition, all forms of conversation slowed the driver's RT. A comparison of the driver talking versus listening found longer RTs for talking than for listening for both the passenger conversation, $t(1,19)=2.10, p=0.05$, and for the cell phone conversation, $t(1,19)=2.09$, $\mathrm{p}=0.05$. A similar analysis of the non-driver also found longer RTs for talking than for listening for both the passenger conversation, $\mathrm{t}(1,19)=3.71, \mathrm{p}=.001$, and for the cell phone conversation, $\mathrm{t}(1,19)=6.13, \mathrm{p}<.001$.

The driving/conversation data were also analyzed using a 2 (driver vs. non-driver) X 2 (cell phone conversation vs. passenger conversation) X 2 (talking vs. listening) split-plot factorial. The data were entered into the statistical analysis based on the between-subjects factor; that is, was the driver talking or listening and was the non-driver talking or listening. In effect, this analysis transposes the DT and DL cells depicted in Figure 1 for the non-driver only. This analysis revealed a significant main effect of talking versus listening, $F(1,38)=34.03, p<.001, \eta^{2}$ $=.472$. None of the other main effects or interactions were significant. The apparent difference in RT between driver and non-driver conversations approached significance, $\mathrm{F}(1,38)=3.64, \mathrm{p}=.064$, $\eta^{2}=.087$. In fact, the marginal effect was caused by one non-driver participant, an outlier with abnormally long RTs compared to other participants in the study. When this participant was removed from the analysis, the driver versus non-driver conversation difference was significant, $\mathrm{F}(1,37)=5.87, \mathrm{p}<.025, \eta^{2}=.129$, as was the main effect of talking versus listening, $\mathrm{F}(1,37)=31.46, \mathrm{p}<.001, \eta^{2}=.460$. None of the other effects or interactions were significant (all p's $>0.1$ ). 


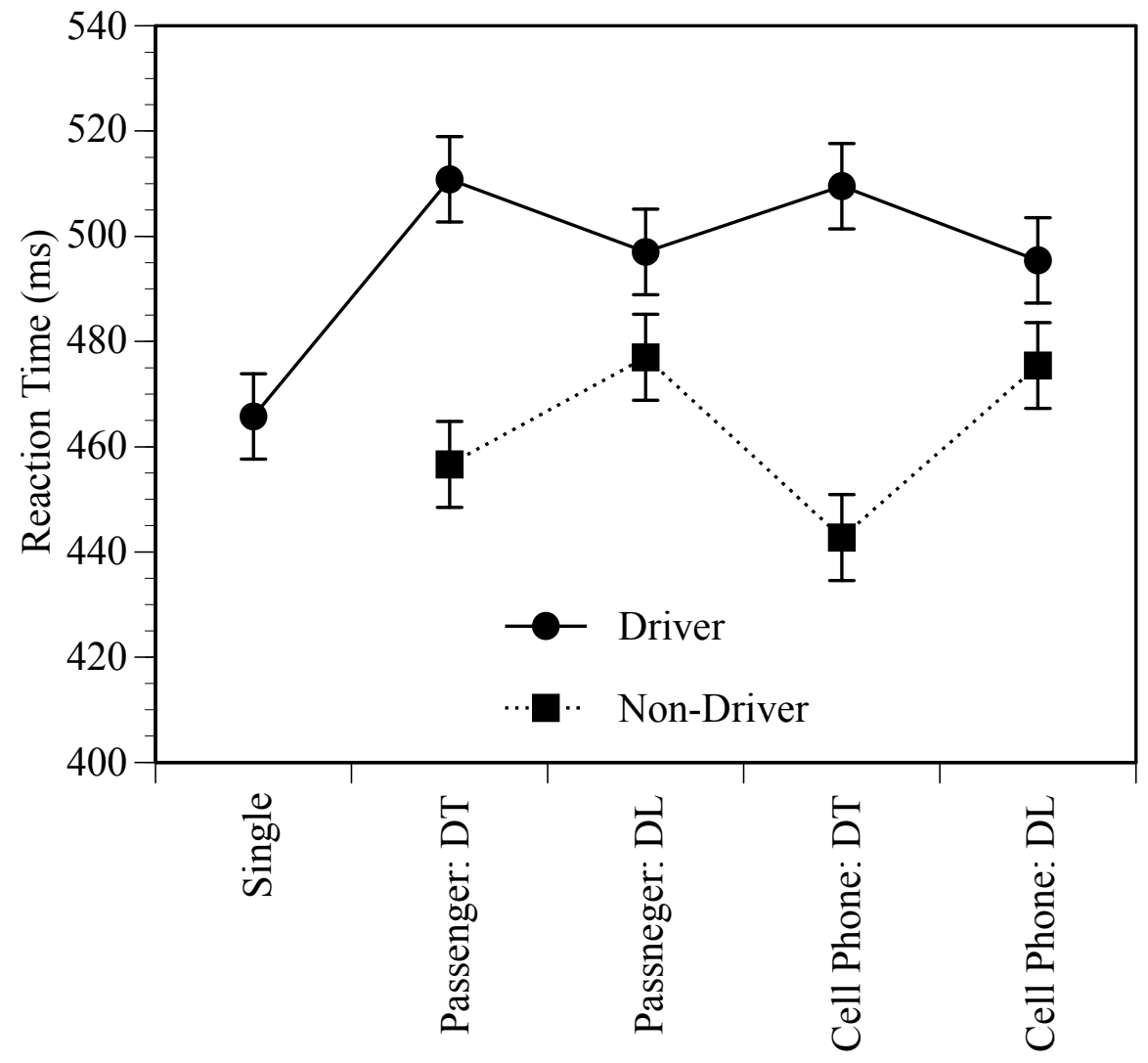

Figure 1. Mean RT as a function of condition. Error bars reflect the standard error of the mean. The "passenger" conditions reflect the passenger conversation for the driver and non-driver. The "cell phone" conditions refer to the cell phone conversations for the driver and non-driver. DT refers to situations when the driver is talking. DL refers to situations where the driver is listening. The single-task condition reflects performance when the driver is driving and not talking to anyone.

\section{CONCLUSION}

This is the first study of its kind to simultaneously measure the dynamic workload of both members of a conversational dyad engaged in natural conversations in a driving context. The workload, as measured using the DRT, was greater for talking than for listening (for a similar conclusion, see Coleman, Turrill, Cooper, \& Strayer, 2016). The pattern obtained with passenger conversations was the same as that obtained with cell phone conversations (for both the driver and the non-driver). The driving task added additional workload to the driver, as evidenced by the difference from the driver's single-task performance and the differences from the non-driving interlocutor.

The difference between talking and listening (approximately $20 \mathrm{~ms}$ ) and between driving and non-driving (approximately $48 \mathrm{~ms}$ ) suggests that the former is more demanding than the latter; however, the standardized effect size, as measured by $\eta^{2}$, for the effect of talking versus listening was greater than for the effect of driving versus non-driving. Thus, the act of speaking (or not) had a more systematic effect on DRT performance than the act of driving (or not) did. The 
effects of driving (or not) and talking (or not) were additive, suggesting that both driver and nondriver were operating in the resource-limited portion of the performance-resource function. In all cases, the slowest RT was observed when the driver was talking (either to a passenger or on a cell phone, they did not significantly differ).

Interestingly, the difference between the driver and non-driver when the driver was listening (and the non-driver was talking) did not differ for either the cell phone or passenger conversation. By contrast, the difference between the driver and non-driver when the driver was talking (and the non-driver was listening) was significant for both the cell phone, $\mathrm{t}(1,37)=3.10, \mathrm{p}=0.004$, and passenger conversations, $\mathrm{t}(1,37)=2.92, \mathrm{p}=0.006$. The DRT revealed a dynamic fluctuation in workload (the saw-tooth pattern) between the conversational dyad, where the person talking was operating under a higher level of workload than the person listening.

As mentioned above, passenger conversations and cell phone conversations are associated with different crash risk profiles. Epidemiological evidence (Rueda-Domingo et al., 2004; Vollrath, Meilinger, \& Kruger, 2002) indicates that the crash rate drops below 1.0 when there is an adult passenger in the vehicle (i.e., there is a slight safety advantage for having another adult passenger in the vehicle, but not for teen driver/passenger dyads, see Carney et al., 2015). By contrast, the epidemiological evidence suggests an elevated crash risk (ranging between 2.2 and 4.0, depending on the method) associated with cell phone conversations (Dingus et al., 2016; Redelmeier \& Tibshirani, 1997; McEvoy et al., 2005). Drews, Pasupathi, and Strayer (2004, 2008) reported that adult passengers are often actively engaged in supporting the driver by pointing out hazards, helping to navigate, and reminding the driver of the task (i.e., exiting at the rest stop). In effect, the passenger acts as "another set of eyes" that helped the driver control the vehicle, and this sort of activity is not afforded by cell phone conversations (see also Gaspar et al., 2014).

These data provide new evidence for dynamic (and reciprocal) fluctuations in the mental workload of the driver and non-driver conversational dyad. When the driver is speaking to an adult passenger in the vehicle, their workload level is relatively high; however, the passenger's workload is lower thereby providing more resources to allocate in support of driving. Although the same fluctuations in workload occur in cell phone conversations, the non-driver does not have access to the information in the driving environment and cannot assist the driver in navigation or hazard identification.

The dual-DRT DRT is an exquisite metric for dynamic fluctuations in workload in a variety of operational environments. In fact, this method can easily be scaled to evaluate the workload experienced in teams where the ebb and flow of workload changes dynamically over complex missions. Importantly, the DRT draws from the residual capacity that has not been consumed by the primary and secondary-tasks (e.g., Strayer et al., 2015). 


\section{REFERENCES}

Carney, C. McGehee, D. ,Harland, K., Weiss,M., \& Raby, M. (2015) Using Naturalistic Driving Data to Assess the Prevalence of Environmental Factors and Driver Behaviors in Teen Driver Crashes. AAA Foundation for Traffic Safety. (March 2015).

Coleman, J. R., Turrill, J., Cooper, J. M., \& Strayer, D. L. (2016). Cognitive workload using interactive voice-messaging systems. Proceedings of the $60^{\text {th }}$ Annual Meeting of the Human Factors and Ergonomics Society, 60, 1887-1891.

Dingus, T. A., Gue, F., Lee, S., Antin, J. F., Oerex, M. Buchanan-King, M., \& Hankey, J. (2016). Driver crash risk factors and prevalence evaluations using naturalistic driving. Proceedings of the National Academy of Sciences, 113, 2636-2641.

Drews, F. A., Pasupathi, M., \& Strayer, D. L. (2008). Passenger and cell-phone conversation during simulated driving. Journal of Experimental Psychology: Applied, 14, 392-400.

Drews, F. A., Pasupathi, M., \& Strayer, D. L. (2004). Passenger and cell-phone conversations in simulated driving. Proceedings of the $48^{\text {nd }}$ Annual Meeting of the Human Factors and Ergonomics Society (pp. 2210-2212).

Gaspar, J. G., Street, W. N., Windsor, M. B., Carbonari, R., Kaczmarski, H., Kramer, A. F., \& Mathewson, K. E. (2014). Providing views of the driving scene to drivers' conversation partners mitigates cell-phone-related distraction. Psychological Science, 25, 2136-2146.

ISO DIS 17488 (2015). Road Vehicles -Transport information and control systems -Detection Response Task (DRT) for assessing selective attention in driving. Draft International Standard, ISO TC 22/SC39/WG8.

McEvoy, S. P., Stevenson, M. R., McCartt, A. T., Woodward, M., Haworth, C., Palamara, P., \& Cercarelli, R. (2005). Role of mobile phones in motor vehicle crashes resulting in hospital attendance: A case-crossover study. British Medical Journal, 331, 428-433.

Redelmeier, D. A., \& Tibshirani, R. J. (1997). Association between cellular-telephone calls and motor vehicle collisions. New England Journal of Medicine, 336(7), 453-458.

Reuda-Domingo, T., Lardelli-Claret, P., Luna-del-Castillo Jde, D., Jimenez-Moleon, J.J., GarciaMartın, M., \& Bueno-Cavanillas, A. (2004). The influence of passengers on the risk of the driver causing a car collision in Spain: Analysis of collisions from 1990 to 1999. Accident Analysis \& Prevention, 36, 481-489, 229 -246.

Strayer, D. L., Drews, F. A., Albert, R. W., \& Johnston, W. A. (2001). Cell phone induced perceptual impairments during simulated driving. In D. V. McGehee, J. D. Lee, \& M. Rizzo (Eds.) Driving Assessment 2001: International Symposium on Human Factors in Driver Assessment, Training, and Vehicle Design. Published by the Public Policy Center, University of Iowa (pp. 14-19).

Strayer, D. L., Turrill, J., Cooper, J. M., Coleman, J., Medeiros-Ward, N., \& Biondi, F. (2015). Assessing cognitive distraction in the automobile. Human Factors, 53, 1300-1324.

Vollrath, M., Meilinger, T., \& Kruger, H. P. (2002). How the presence of passengers influences the risk of a collision with another vehicle. Accident Analysis and Prevention, 34, $649-654$. 